\title{
The Effects of a Knee Joint Injury Prevention Program on Young Female Basketball Players: A Systematic Review
}

\author{
Miljan Hadzovic ${ }^{1}$, Predrag Ilic $^{1}$, Ana Lilic ${ }^{1}$, Mima Stankovic ${ }^{1}$ \\ 'University of Nis, Faculty of Sport and Physical Education, Nis, Serbia
}

\begin{abstract}
The research results referring to frequency have indicated that most of the sports injuries among athletes of both genders occur in basketball and that knee injury is the second most frequent injury during sports activities. The anterior cruciate ligament (ACL) represents one of the four most important connections for knee stability, and it is frequently prone to injury during sports activities. The aim of this paper was to determine the effects of an exercise program on the prevention of injury to the anterior cruciate ligament of the knee joint among young female basketball players. To collect existing research on the effects of the applications of prevention programs on the prevention of $A C L$ injury in young female basketball players, the following electronic databases were searched: PubMed, SCIndeks, PEDro, J-GATE, DOAJ and Google Scholar. The analyzed studies were published between 2003 and 2018 and the participants were young female basketball players. According to the results of this study, the most frequently used training programs were neuromuscular programs, whose structure includes several types of exercises and which represented a combination of plyometric exercises, core strengthening exercises, exercises to strengthen the muscles of the lower extremities, agility exercises, flexibility exercises, and balance exercises. Finally, the application of the knee injury training program leads to an improvement in motor balance, proprioceptive abilities, balance, flexibility, as well as biomechanical abilities related to injuries of the $\mathrm{ACL}$, leading to an improvement in sports performance among female basketball players.
\end{abstract}

Keywords: Neuromuscular Training, ACL, Sports Injury

\section{Introduction}

The emergence of television and directly televised sporting events, along with the desire to increase profit, have increased the popularity of certain sports among most of the global population, which has in turn led to a spike in the number of games and thus to increased movement and higher frequency of injuries among professional athletes (Matijević, 2014). Researches have indicated that female athletes who take part in sports such as basketball, volleyball, handball and football, which are dominated by jumps, pivots, frequent and rapid changes in the direction of movement, have a four to six times greater risk of injury of the knee joint than male athletes who take part in the same sports (Hewett, Stroupe,
Nance, \& Noyes, 1996; Huston \& Wojtys, 1996; Hewett, 2000). The increased risk of various injuries to the knee joint can be explained by the increased role of the valgus, which depends on the landing, that is, the specificities of each sport (Herrington, 2011). The research results referring to frequency have indicated that most of the sports injuries among athletes of both genders occur in basketball and that knee injury is the second most frequent injury, second only to injury of the ankle (Haycock \& Gillette, 1976; Whiteside, 1980; Zelisko, Noble, \& Porter, 1982).

As one of the most complex and largest joints of the human body, due to increased load of the locomotor system, the knee joint is prone to injury. This is a very frequent type of injury both

Correspondence:

Montenegro Miljan Hadzovic

Sport University of Nis, Faculty of Sport and Physical Education, Carnojevica 10A, Nis 18000, Serbia E-mail: miljanhadzovic@gmail.com 
among children and young adults, but also among athletes and the elderly. Knee injuries such as contusions, hematoma, fractures of the kneecap, fractures of other segments of the joint, and torn ligaments, are a consequence of increased movement or taking part in sports activities, a result of the direct or indirect effects of mechanical forces (Kosinac, 2002). In addition to these injuries caused by the effects of mechanical forces, certain deformities can also occur in the knee during the growth and development of the child, the most frequent of which is "knock-knees" (genu valgum) and "bowing" at the knee (genu varum), which may be a consequence of rickets, a weak diet, obesity and increased static load during standing or walking (Ulić, 1997). The knee joint connects the upper leg and the lower leg and includes three smaller joints, that is, the joint of the femur and tibia, the joint of the femur and kneecap, and the upper joint between the tibia and fibula. The movements which are performed in this joint are flexion, extension, and internal and external rotation (Müller, 1983). In the frontal plane, the normal curvature of the knee joint is $174^{\circ}$ (the valgus position), and any and all smaller or greater deviations from this angle are labeled as "varus" or "valgus" knees, while the normal curvature in the sagittal plane has a value of $180^{\circ}$, thus an angle exceeding $185^{\circ}$ among women and hyperextension among men is known as genu recurvatum (Begović, 2016). Furthermore, it is well known that the angle between the upper leg and lower leg (,valgus" of the knee) is greater among women, due to a wider and more shallow pelvic bone, as well as a shorter femur (Kosinac, 2002). For the functional stability of the knee, two types of stabilizers are responsible - the insertions of the surrounding muscles which generate force movement and stop movement, which can be active and passive, and which include surfaces of the joints, the tendons, menisci, joint capsules and gravitational force which limits the movement of the knee (Savić, 1999, taken from Đuričin, 2018). The anterior cruciate ligament (ACL - ligamentum cruciatum anterius) represents one of the four most important connections for knee stability, and it is frequently prone to injury during sports activities (Aglietti, Buzzi, Zaccherotti, \& De Biase, 1994, Frank \& Jackson, 1997; Hewett et al., 2005)

The aim of this paper was to determine the effects of an exercise program on the prevention of injury to the anterior cruciate ligament of the knee joint among young female basketball players. The tasks related to the goals of the research included: 1 ) searching electronic databases; 2) a compilation and translation of the literature from English; 3) analysis of the research results; and 4) presentation of the results, that is determining the effects of a sports injury prevention training program for the anterior cruciate ligament in the knee joint. After compiling the relevant data from the previously carried out experimental research dating from 2003 to 2018, and under the assumption that the exercise programs affect the stability and decrease in the number of injuries to the knee joint among female basketball players, an evaluation of the effects was carried out.

\section{Method}

To collect existing research on the effects of the applications of prevention programs on the prevention of anterior cruciate ligament injury in the knee joint in young female basketball players, the following electronic databases were searched: PubMed, SCIndeks, PEDro, J-GATE, SCIndes, DOAJ and Google Scholar. The analyzed studies were published between 2003 and 2018. When surveying the databases, the following keywords were used: physical activity, knee valgus, landing, kinematics, ACL injury mechanism. The titles of the studies were identified, as were the abstracts and entire texts, which were then read and analyzed. The research was carried out by four authors, and the studies were analyzed in detail based on the set criteria.
For an experimental study to be included in the final analysis, it had to satisfy certain criteria: the participants in the research were individuals not afflicted by any chronic conditions, the participants were female basketball players of an average age of 15 to 23 , the experimental group took part in a sports injury prevention training program for the knee joint on a sample of female basketball players, where measurements were taken and the effects of the applied program were evaluated, the research was written in English.

The experimental studies which met the set criteria were then analyzed and presented based on the following parameters: references (the initial of the author and year of publication), the sample of participants (health status, age, overall number and subgroups), the physical exercise program, the duration and frequency of the exercise, the intensity of the exercise, the research results.

The exclusion criteria included: studies which included only male participants, studies which included female participants whose average age did not range from 15 to 23, papers not published in English. This systematic review was undertaken in accordance with the Preferred Reporting Items for Systematic Reviews and Meta-Analyses (PRISMA) statement (Moher, Liberati, Tetzlaff, \& Altman, 2009).

\section{Results}

The survey of the electronic databases resulted in 986 studies on the topic of choice, primarily 524 studies were eliminated as duplicates, then 419 papers were rejected based on abstracts, while 33 studies were excluded and based on age and gender of the subjects, or were not written in English (graph 1). A further analysis and application of the set criteria, in accordance with the goals of this study, identified 10 experimental research programs which were included in the final analysis (Wilkerson et al., 2004; Chappell \& Limpisvasti, 2008; Kato, Urabe, \& Kawamura, 2008; Vescovi, Canavan, \& Hasson, 2008; Lim et al., 2009; McLeod, Armstrong, Miller, \& Sauers, 2009; Herrington, 2010; Nagano, Ida, Akai, \& Fukubayashi, 2011; Bonato, Benis, \& La Torre, 2018; Li, Liu, \& Zhang, 2018).

\section{Discussion}

Due to the increased number of matches, knee injuries are a frequent occurrence in intermittent sports with an increased number of jumps and rapid changes in rhythm and direction of movement, with a greater frequency of occurrence among female athletes than male ones (Dugan, 2005). The greater number of knee injuries among the female athletes is conditioned by the decrease in hip flexion and the knee during landing, instability of the knee joint, increased activation of the quadriceps and decreased activation of the knee tendon, which could lead to an increased risk of non-contact related injury of the anterior cruciate ligament (Chappell, Creighton, Giuliani, Yu, \& Garrett, 2007).

Instability of the knee joint is defined as anterior, posterior, medial, lateral and rotational in relation to the movement of the lower leg, while the main structures which provide stability are the anterior cruciate ligament (ACL - ligamentum cruciatum anterius), the posterior cruciate ligament (PCL - ligamentu cruciatum posterius), the fibular collateral ligament (LCL - ligamentum collaterale laterale) and the medial collateral ligament (MCL - ligamentum collaterale mediale), (Begović, 2016). Bearing in mind that injury to the ACL is one of the most frequent injuries among female basketball players (Sallis, Jones, Sunshine, Smith \& Simon, 2001 ), the aim of this research was to find effective exercise programs which could be used to prevent injury of this type in the knee joint among female basketball players.

The research results, presented in table form (Table 1), indicate that in all the analyzed studies included programs which use a combination of multiple types of exercises to strengthen the 


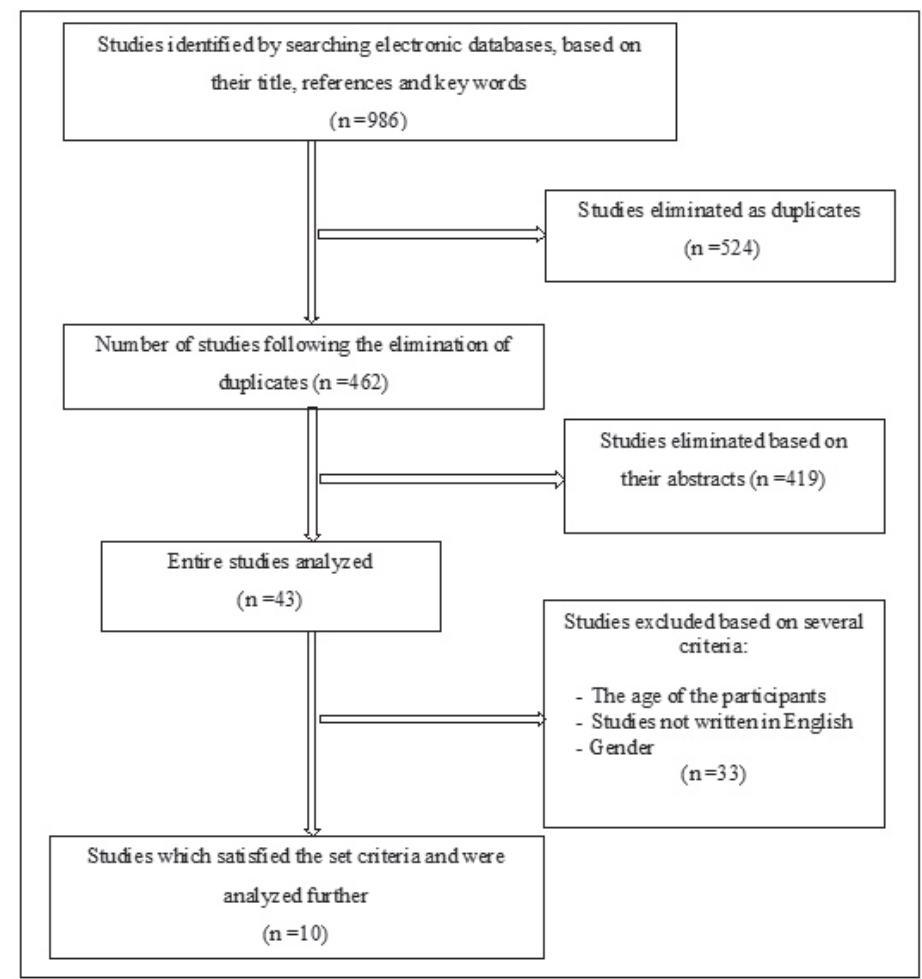

Graph 1: A diagram of the course of analysis of the papers

muscles of the torso and the lower extremities, plyometric exercises, exercises to increase flexibility and balance, while the control group followed a regular basketball training program. As part of the introductory segment of regular basketball training during the course of the week, preventive programs were used in seven of the analyzed studies (Chappell \& Limpisvasti, 2008; Kato et al., 2008; Lim et al., 2009; Herrington, 2010; Nagano et al., 2011; Bonato et al., 2018; Li et al., 2018). Two studies included specially organized training sessions for the prevention of injuries to the knee joint (Vescovi et al., 2008; McLeod et al., 2009), while one study carried out preventive exercises as part of the pre-season conditioning training (Wilkerson et al., 2004).

The training structure of the analyzed experimental training programs differed. The functional strengthening of the muscles of the lower extremities and exercises for the development of strength were used in all the analyzed studies, as one of the important factors in the prevention programs for noncontact injury to the ACL. In one study (Vescovi et al., 2008) the authors cited that in addition to the small sample of participants who took part in prevention program, the statistical progress in strength was another of the more important shortcomings. Core strengthening exercises were especially prominent as part of the prevention programs in five studies (Chappell \& Limpisvasti, 2008; Lim et al., 2009; Herrington, 2010; Bonato et al., 2018; Li et al., 2018). Plyometric exercises were a constituent part of the program for the prevention of ACL injuries in all the studies, which were included to improve the mechanics and reduce force during landing. Seven of the analyzed studies included balance exercises in their programs (Chappell \& Limpisvasti, 2008; Kato et al., 2008; McLeod et al., 2009; Herrington, 2010; Nagano et al., 2011), while four of the studies used agility exercises with rapid changes in intensity and direction of movement (Lim et al.,2009; McLeod et al., 2009; Herrington, 2010; Bonato et al., 2018).

The systematic overview of the included parameters noted a statistically significant effect of the exercise on the maximal angle of knee flexion in a study which included the so-called SIPTP
(Sports Injury Prevention Training Program), which lasted for a period of eight weeks (Lim et al., 2009) and in a study which included a neuromuscular training program that lasted for a period of six weeks (Chappell \& Limpisvasti, 2008). There were no statistically significant effects in the study which was based on combined popular exercise training and balance exercises for a period of four weeks (Kato et al., 2008), which could be a consequence of the shorter duration of the program and the lower frequency of training sessions during the week. The specialized training program for injury prevention carried out in one of the studies (Lim et al., 2009) had a statistically significant influence on the increase in the distance between the knees, the decrease in the knee joint torque in extension and at the same time an increase in the abduction torque, which is in accordance with the claims made by previous authors, that this type of neuromuscular training enables female athletes to adapt and protect their ACL from high impulse load (Hewett, Myer, \& Ford, 2006).

The results of one of the analyzed studies have indicated that the decrease in risk of injury to the ACL can be influenced by plyometric training with a duration of six weeks, which influences the improvement of the neuromuscular attributes, that is, influences the ratio between the lower leg and quadriceps (Wilkerson et al., 2004).

Progressive jump training over a period of four weeks, in one of the analyzed studies (Herrington, 2010), led to a statistically significant reduction in the angle of the knee in the valgus position during landing (for both legs). These results are similar to those of previous studies in which combined training was applied over an extended period of six weeks (Noyes., Barber-Westin, Fleckenstein, Walsh, \& West, 2005).

In one of the analyzed studies ( $\mathrm{Li}$ et al., 2018), neuromuscular training for a period of four weeks led to a statistically significant decrease in the reaction force to the surface, but not to any significant changes in the knee flexion, while in another study (Vescovi et al., 2008) plyometric training for a period of six weeks led to a decrease in the vertical reaction force of $17 \%$ to $18 \%$ in the case 


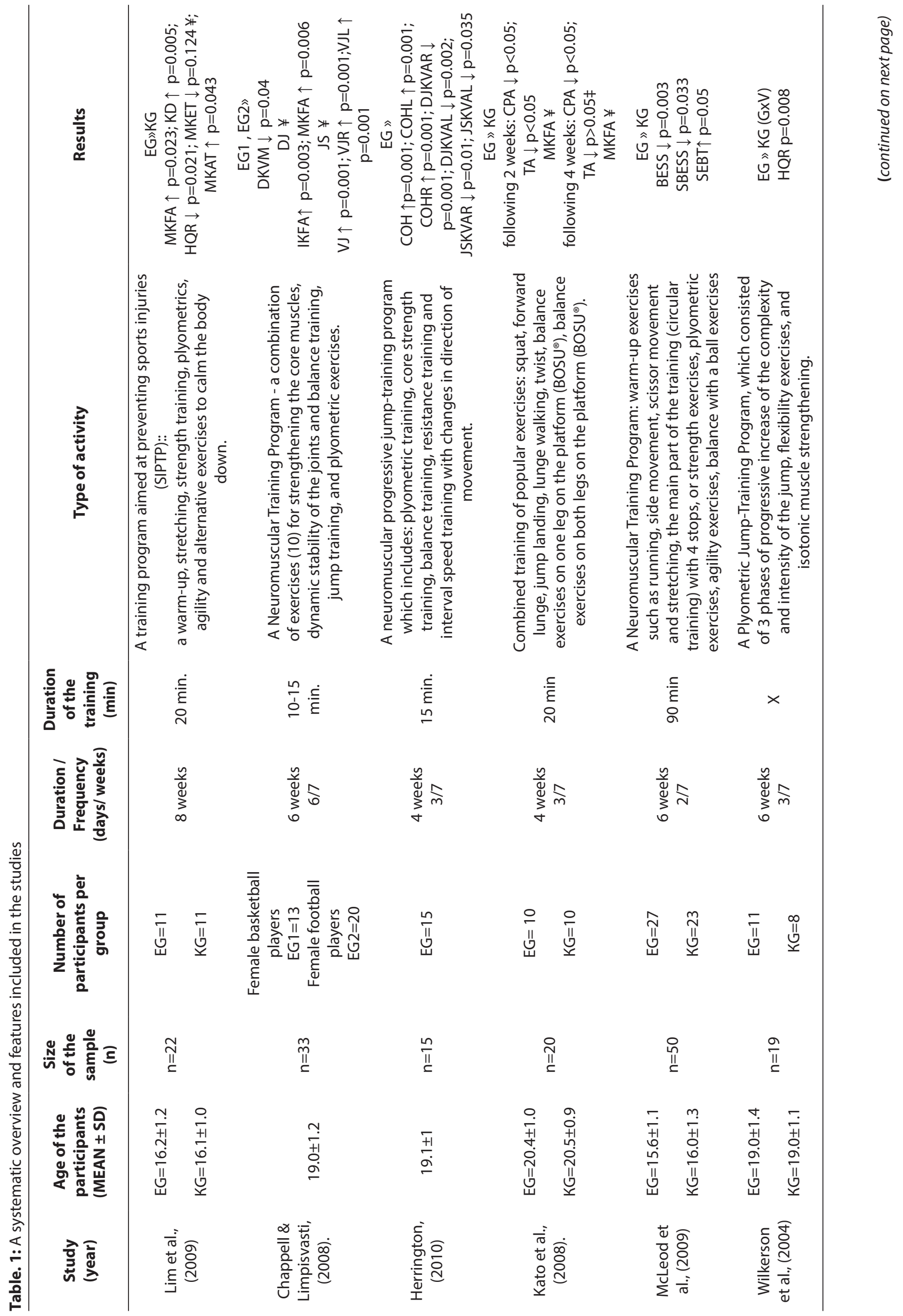




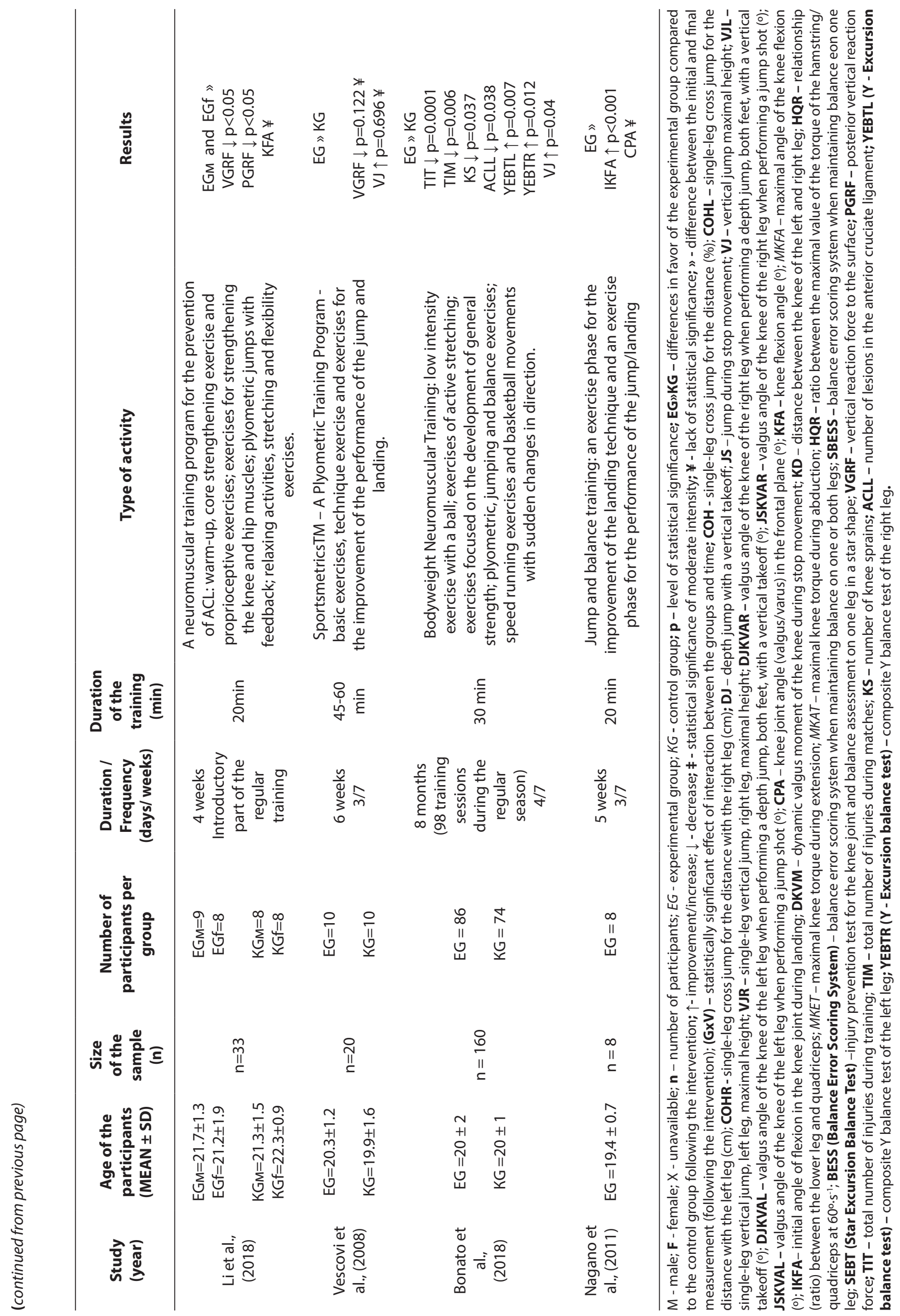


of most of the female participants of the experimental group. The change was not statistically significant, but had clinical significance. The neuromuscular training also had an effect on the motor balance among female basketball players and can lead to a decrease in the risk of injury to the knee joint (McLeod et al., 2009).

Combined training programs, which in their structure contain strength exercises, jumps, and balance exercises (Kato et al., 2008) for a duration of four weeks, led to a statistically significant decrease in the angle of the knee joint (valgus/varus) in the frontal plane, while the application of the program consisting of jumps and balance exercises for a period of five weeks did not statistically significantly affect changes in this joint in the frontal plane, which could be a consequence of the lack of exercises for strengthening the muscles of the lower extremities.

By analyzing the compiled studies, it was concluded that there are several different programs which have a positive effect on the prevention of injury to the ACL in the knee joint among female basketball players. According to the results of this study, in the current research the most frequently used training programs are neuromuscular programs, whose structure includes several types of exercises and which represent a combination of plyometric exercises, core strengthening exercises, exercises to strengthen the muscles of the lower extremities, agility exercises, flexibility exercises, and balance exercises. Even though there are programs with a somewhat shorter duration, the greatest effects on the prevention of injury to the knee joint among female basketball players were realized in programs with a frequency of three training sessions per week, for a period of six or more weeks.

Finally, the application of the prevention training program for knee injury represents a very important part of every organized and planed training process, since it leads to an improvement in motor balance, proprioceptive abilities, balance, flexibility, as well as biomechanical abilities related to injuries of the ACL, leading to an improvement in the sports performance among female basketball players.

\section{Acknowledgements}

There are no acknowledgements.

\section{Conflict of Interest}

The authors declare that there are no conflicts of interest.

Received: 8 September 2019 | Accepted: 18 November 2019 | Published: 10 January 2020

\section{References}

Aglietti, P., Buzzi, R., Zaccherotti, G., \& De Biase, P. (1994). Patellar tendon versus doubled semitendinosus and gracilis tendons for anterior cruciate ligament reconstruction. The American journal of sports medicine, 22(2), 211-218.

Begović, N.N. (2016). Utvrđivanje faktora rizika idiopatskog bola u kolenu kod adolescenata. Neobjavljena doktorska disertacija. Beograd: Univerzitet u Beogradu, Medicinski fakultet.

Bonato, M., Benis, R., \& La Torre, A. (2018). Neuromuscular training reduces lower limb injuries in elite female basketball players. A cluster randomized controlled trial. Scandinavian journal of medicine \& science in sports, 28(4), 1451-1460.

Chappell, J.D., \& Limpisvasti, O. (2008). Effect of a neuromuscular training program on the kinetics and kinematics of jumping tasks. The American journal of sports medicine, 36(6), 1081-1086.

Chappell, J.D., Creighton, R.A., Giuliani, C., Yu, B., \& Garrett, W.E. (2007) Kinematics and electromyography of landing preparation in vertical stop-jump: risks for noncontact anterior cruciate ligament injury. The American journal of sports medicine, 35(2), 235-241.

Dugan, S.A. (2005). Sports-related knee injuries in female athletes: what gives? American journal of physical medicine \& rehabilitation, 84(2), 122-130.

Đuričin, A. (2018). Prostorno određivanje položaja kalema u golenjači posle rekonstrukcije prednjeg ukrštenog ligamenta kolena. Neobjavljena doktorska disertacija. Novi Sad: Univerzitet u Novom Sadu, Medicinski fakultet.

Frank, C.B., \& Jackson, D.W. (1997). The science of reconstruction of the anterior cruciate ligament. The Journal of Bone \& Joint Surgery, 79(10), 1556-1576.

Haycock, C.E., \& Gillette, J. V. (1976). Susceptibility of women athletes to injury: myths vs reality. Jama, 236(2), 163-165.

Herrington, L. (2010). The effects of 4 weeks of jump training on landing knee valgus and crossover hop performance in female basketball players. The Journal of Strength \& Conditioning Research, 24(12), 34273432.

Herrington, L. (2011). Knee valgus angle during landing tasks in female volleyball and basketball players. The Journal of Strength \& Conditioning Research, 25(1), 262-266.

Hewett, T.E. (2000). Neuromuscular and hormonal factors associated with knee injuries in female athletes. Sports medicine, 29(5), 313-327.

Hewett, T.E., Myer, G.D., \& Ford, K.R. (2006). Anterior cruciate ligament injuries in female athletes: Part 1, mechanisms and risk factors. The American journal of sports medicine, 34(2), 299-311.

Hewett, T.E., Stroupe, A.L., Nance, T.A., \& Noyes, F.R. (1996). Plyometric training in female athletes: decreased impact forces and increased hamstring torques. The American journal of sports medicine, 24(6), 765773.

Hewett, T., Myer, G., Ford, K., Heidt, R., Colosimo, A., McLean, S., van den Bogert, A., Paterno, M., \& Succop, P. (2005). Biomechanical measures of neuromuscular control and valgus loading of the knee predict anterior cruciate ligament injury risk in female athletes: a prospective study. The American journal of sports medicine, 33(4), 492-501.

Huston, L.J., \& Wojtys, E.M. (1996). Neuromuscular performance characteristics in elite female athletes. The American journal of sports medicine, 24(4), 427-436.

Kato, S., Urabe, Y., \& Kawamura, K. (2008). Alignment control exercise changes lower extremity movement during stop movements in female basketball players. The Knee, 15(4), 299-304.

Kosinac, Z. (2002). Kineziterapija sustava za kretanje. Split: Udruga za šport rekreaciju djece i mladeži grada Splita.

Li, H., Liu, H., \& Zhang, X. (2018). The effectiveness of neuromuscular training with augmented feedback on acl injury prevention. ISBS Proceedings Archive, 36(1), 948-951.

Lim, B.O., Lee, Y.S., Kim, J.G., An, K.O., Yoo, J \& Kwon, Y.H (2009). Effects of sports injury prevention training on the biomechanical risk factors of anterior cruciate ligament injury in high school female basketball players. The American journal of sports medicine, 37(9), 1728-1734.

Matijević, R. (2014). Propriocepcija zgloba kolena posle kidanja prednjeg ukrštenog ligamenta kod profesionalnih sportista. Neobjavljena doktorska disertacija. Novi Sad: Univerzitet u Novom Sadu, Medicinski fakultet.

McLeod, T.C.V., Armstrong, T., Miller, M., \& Sauers, J.L. (2009). Balance improvements in female high school basketball players after a 6-week neuromuscular-training program. Journal of sport rehabilitation, 18(4), 465-481.

Moher, D., Liberati, A., Tetzlaff, J., \& Altman, D. G. (2009). Preferred reporting items for systematic reviews and meta-analyses: the PRISMA statement. Annals of internal medicine, 151(4), 264-269.

Müller, W. (1983). The knee: form, function, and ligament reconstruction. Berlin: Springer Science \& Business Media.

Nagano, Y., Ida, H., Akai, M., \& Fukubayashi, T. (2011). Effects of jump and balance training on knee kinematics and electromyography of female basketball athletes during a single limb drop landing: pre-post intervention study. Sports Medicine, Arthroscopy, Rehabilitation Therapy \& Technology, 3(1), 1-8.

Noyes, F.R., Barber-Westin, S.D., Fleckenstein, C., Walsh, C., \& West, J. (2005) The drop-jump screening test: difference in lower limb control by gender and effect of neuromuscular training in female athletes. The American journal of sports medicine, 33(2), 197-207.

Sallis, R.E., Jones, K., Sunshine, S., Smith, G., \& Simon, L. (2001). Comparing sports injuries in men and women. International journal of sports medicine, 22(06), 420-423.

Ulić, D. (1997). Osnove kineziterapije. Novi Sad: Faculty of Physical Education.

Vescovi, J.D., Canavan, P.K., \& Hasson, S. (2008). Effects of a plyometric program on vertical landing force and jumping performance in college women. Physical Therapy in Sport, 9(4), 185-192.

Whiteside, P. A. (1980). Men's and women's injuries in comparable sports. The Physician and sports medicine, 8(3), 130-140.

Wilkerson, G.B., Colston, M.A., Short, N.I., Neal, K.L., Hoewischer, P.E., \& Pixley, J.J. (2004). Neuromuscular Changes in Female Collegiate Athletes Resulting From a Plyometric Jump-Training Program. Journal of Athletic Training, 39(1), 17-23.

Zelisko, J.A., Noble, H.B., \& Porter, M. (1982). A comparison of men's and women's professional basketball injuries. The American journal of sports medicine, 10(5), 297-299. 